\title{
Setting Maximum Mortality Limits for Harbour Porpoises in Dutch Waters to Achieve Conservation Objectives
}

\author{
Meike Scheidat $^{1 *}$, Russell Leaper ${ }^{2}$, Martine Van Den Heuvel-Greve ${ }^{3}$, Arliss Winship ${ }^{4}$ \\ ${ }^{1}$ IMARES Wageningen UR, IJmuiden, The Netherlands \\ ${ }^{2}$ School of Biological Sciences, University of Aberdeen, Aberdeen, UK \\ ${ }^{3}$ IMARES Wageningen UR, Yerseke, The Netherlands \\ ${ }^{4}$ Institute of Marine Sciences, University of California, Santa Cruz, USA \\ Email: *meike.scheidat@wur.nl
}

Received February 28, 2013; revised March 6, 2013; accepted April 8, 2013

Copyright (C) 2013 Meike Scheidat et al. This is an open access article distributed under the Creative Commons Attribution License, which permits unrestricted use, distribution, and reproduction in any medium, provided the original work is properly cited.

\begin{abstract}
Harbour porpoises in the North Sea are protected under national and EU legislation, and under the regional agreement ASCOBANS, within the UN Convention on Migratory Species. As yet, no methods exist to quantify the cumulative impacts of direct anthropogenic mortality (e.g. by-catch) and indirect effects of human activities (e.g. contaminants) on porpoise populations. However, procedures do exist for assessing whether total anthropogenic mortality may result in failure to meet conservation objectives. While the ultimate aim is to reduce the number of such deaths to zero, ASCOBANS has an interim objective to reduce anthropogenic mortality to a level that will allow recovery of populations. Several different criteria have been proposed as limits to anthropogenic mortality that may still allow conservation objectives to be met. These criteria include simple percentages of the best population abundance estimate and more complex procedures that account for uncertainty and other information about the population. In this paper, we report new estimates of abundance for porpoises in Dutch waters, and we apply several methods to calculate maximum anthropogenic mortality limits from these estimates. We considered whether these mortality limits would meet the objective of the ASCOBANS agreement and other international obligations, and how these limits may be applied at a national level rather than the biological population level. The current simple approach of a limit of $1.7 \%$ of the best abundance estimate may not satisfy conservation objectives. We recommend the use of management procedures for setting mortality limits that take into account available data including associated uncertainties and biases, and whose performance has been extensively tested through simulation.
\end{abstract}

Keywords: Harbour Porpoise; By-Catch; Management; Mortality Limits; North Sea

\section{Introduction}

Harbour porpoises are small toothed whales occurring in the northern hemisphere and are the most common cetacean in the North Sea. Concerns about their conservation status were raised in the 1990s because of threats from human activities [1]. The southern North Sea is used extensively by humans, and porpoises are subject to potentially negative anthropogenic impacts, ranging from chronic effects of contaminants and noise, to incidental death through by-catch (e.g. reviewed in [2,3]).

In recent decades national and international agreements developed conservation and management frameworks for this species. The ultimate aim of ASCOBANS (Agreement on the Conservation of Small Cetaceans of the Bal-

${ }^{*}$ Corresponding author. tic and North Seas) is to reduce human induced mortalities of small cetaceans to zero and "to restore and/or maintain biological management stocks of small cetaceans at a level they would reach when there is the lowest possible anthropogenic influence" [4]. However, ASCOBANS' interim objective is "to restore and/or maintain stocks/populations to $80 \%$ or more of the carrying capacity" [5]. In 2000, the immediate precautionary objective of ASCOBANS was stated as "to reduce bycatches to less than $1 \%$ of the best available population estimate" [4]. At the time, removals of greater than 1.7\% of the population were believed to put the population at a high risk of not maintaining $80 \%$ of carrying capacity and were considered unacceptable by ASCOBANS.

Mortality limits based on a simple percentage of estimated population size do not account for uncertainties 
and biases in abundance and mortality estimates, or incorporate supplementary information about the population (e.g. past abundance and mortality estimates). Alternative procedures for calculating anthropogenic mortality limits have been developed for marine mammal populations. For example, the Potential Biological Removal (PBR) procedure was designed to meet the requirement of the US Marine Mammal Protection Act that populations be allowed to recover to, or be maintained at, a size greater than their maximum net productivity level [6]. The PBR approach calculates a mortality limit as a function of a recent 'minimum' estimate of abundance that accounts for uncertainty. Another management procedure, the Revised Management Procedure (RMP) of the International Whaling Commission, was developed to determine sustainable catch limits for baleen whale populations [7]. The Catch Limit Algorithm (CLA) which forms the core of the RMP uses a time series of one or more abundance estimates (with associated estimates of uncertainty), and a series of annual historical catches to calculate a catch limit [8]. The CLA accounts for uncertainty in population abundance estimates, productivity and status, and can utilize time series of abundance and catch data. Both the PBR and RMP approaches were developed using simulation frameworks that tested the expected performance of the procedures under a wide range of scenarios [9].

The PBR approach has been applied outside of the US to calculate mortality limits for harbour porpoise populations in the Baltic region [10], Canadian waters [11] and the North Sea as a whole [12]. Those studies used simulations to determine the PBR "recovery factor" multiplier that would be expected to achieve the ASCOBANS' interim objective. Winship [12] also applied a version of the CLA to calculate mortality limits for harbour porpoise in the North Sea, and tuned the procedure for the ASCOBANS' interim objective.

Harbour porpoises were common in Dutch waters up to the 1940s but then became scarce and were sighted only rarely (e.g. [13]). In the 1990s both sighting and stranding records increased again (e.g. [14-16]), most likely due to a shift in distribution $[17,18]$. Today porpoises occur in Dutch waters year round with estimated abundances ranging from 26,000 in the summer to 85,000 in the early spring $[19,20]$. They are part of a larger population within the North Sea with seasonal variations in density suggesting movements between areas. The stock structure of harbour porpoise populations has been investigated using skeletal differences, genetic analyses, contaminant loads, parasite loads, dietary preferences and telemetry (reviewed in [21]). The results indicate some separations in subpopulations and two management units for the North Sea have been proposed [21]. While the conservation implications of threats to the North Sea porpoises should ideally be assessed at the level of management units, data collection and management actions are often undertaken at a national level.

In this paper we use The Netherlands as a case study to demonstrate the current situation faced by a number of European countries for setting limits to anthropogenic mortality and the difficulties associated with current mortality thresholds. We use new abundance estimates recently obtained for harbour porpoises in The Netherlands to examine options for setting anthropogenic mortality limits that would be expected to meet specified conservation objectives. In particular we focus on the conservation aim formulated by ASCOBANS of restoring or maintaining a population at $80 \%$ of its carrying capacity. Although not specified by ASCOBANS we interpret the intent of this objective as requiring a high probability that it would be met, and so present limits based on achieving the objective with a $95 \%$ probability. We consider mortality limits based on simple percentages, the PBR approach, and previously calculated limits for the entire North Sea. The goal of this paper is to assess and recommend current procedures for setting mortality limits for the Dutch part of the North Sea that would be expected to meet conservation objectives at a population level if all North Sea countries followed a similar approach.

\section{Methods}

\subsection{Abundance Estimates}

Abundance estimates from dedicated aerial surveys were used as a basis for the mortality limit calculations [20]. Surveys were conducted in spring (March 2011), summer (July 2011) and fall (October/November 2011) in the Dutch Continental Shelf (Figure 1). The resulting density and abundance estimates are given in Table 1. Details about the survey methodology can be found in Scheidat et al. [19]. The surveys were conducted at approximately 4 month intervals, so the average of the three estimates was taken as the best estimate of the annual average abundance.

Three survey blocks from the SCANSII survey in July 2005 (B,U,H) overlapped with the Dutch EEZ, with the majority of the EEZ covered by block U (Figure 1). These had estimated densities varying from 0.331 to 0.562 individuals $\mathrm{km}^{-2}$. The average density for the Dutch EEZ over one year was very similar to the estimated density for the whole of SCANSII block U in July [17].

From the density estimates in Table 1, it seems likely that there are seasonal shifts in the distribution of harbour porpoises in the North Sea in and out of Dutch waters following a similar pattern to recorded shifts closer to the coast [18]. This raises the question of which abun- 


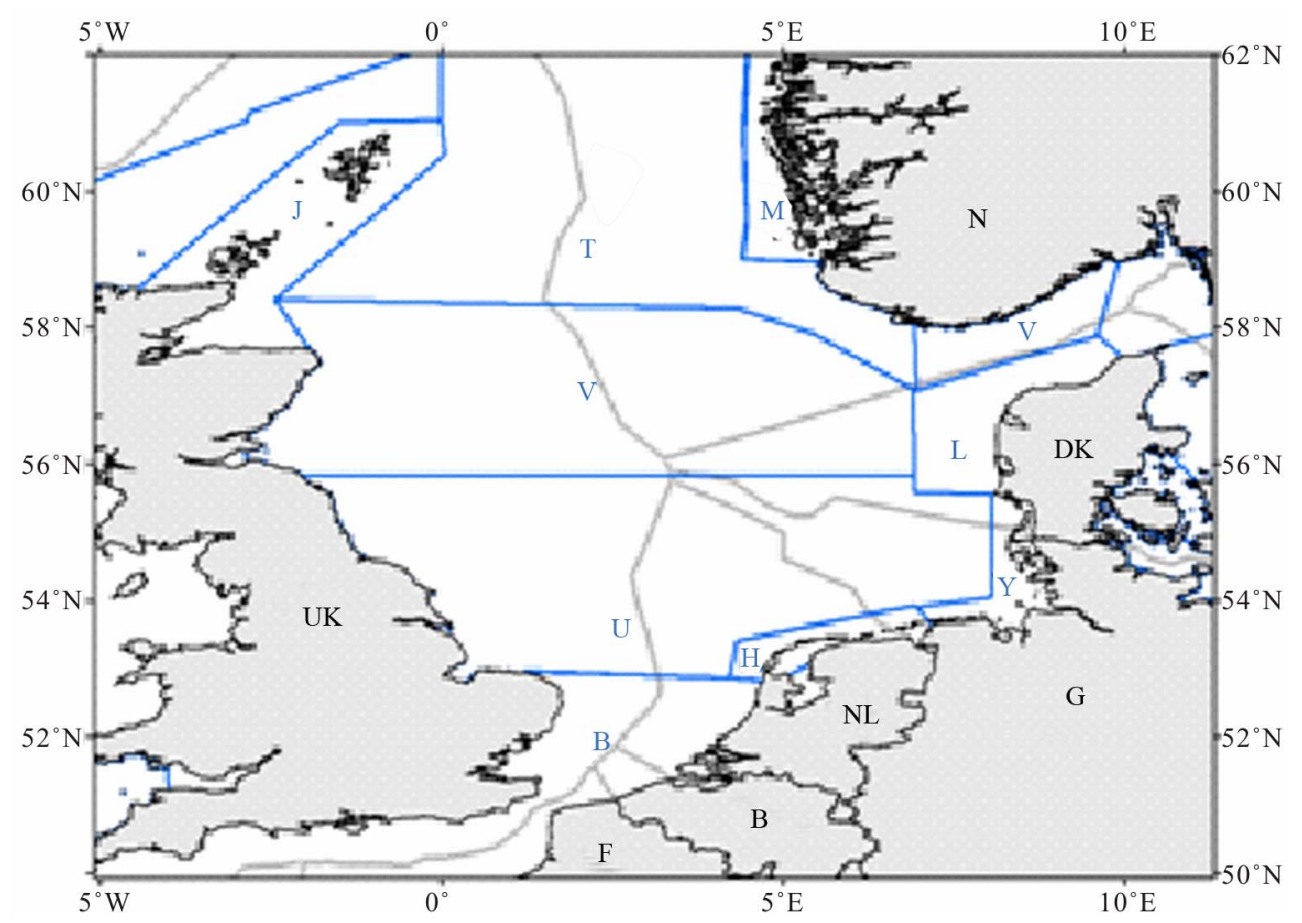

Figure 1. Overview of the SCANSII study areas for the North Sea: J, T, M (north); V, L (central) and B, U, H, Y (south) and the EEZ waters of Belgium (B), Denmark (DK), Germany (G), France (F), The Netherlands (NL), Norway (N) and the United Kingdom (UK). All waters shown here are covered in the ASCOBANS agreement.

Table 1. Density and abundance estimates for harbour porpoises in the Dutch EEZ (including national waters) (from [20]).

\begin{tabular}{cccc}
\hline Survey time & Density $\left(\right.$ animals $\left./ \mathrm{km}^{2}\right)[95 \%$ C.I. $]$ & Abundance $(\mathrm{n}$ animals) $[95 \%$ C.I. $]$ & C.V. \\
\hline July 2010 & $0.438[0.236-0.903]$ & $25998[13988-53623]$ & 0.336 \\
Oct/Nov 2010 & $0.505[0.271-0.994]$ & $29963[16098-59011]$ & 0.332 \\
March 2011 & $1.441[0.830-2.786]$ & $85572[49324-165443]$ & 0.316 \\
\hline
\end{tabular}

dance estimate to use for setting mortality limits. If the sources of mortality (e.g., fisheries in which by-catch occurs) operate year round then the average annual abundance may be the most appropriate. If there is seasonal variation in sources of mortality then it may be most appropriate to use the abundance estimate corresponding to the season when most mortality occurs. However, it is important to note that in order to achieve conservation objectives at the population level, national mortality limits should be calculated on the basis of abundance estimates from the same time of year, so seasonal patterns of mortality sources outside of Dutch waters are also a consideration. At present there is insufficient information to identify any seasonal patterns in mortality risk so we based our mortality limits on the average abundance during the year.

\subsection{Anthropogenic Mortality Limits}

We calculated anthropogenic mortality limits using three approaches. First, we calculated limits as simple per- centages of the average annual abundance estimate for Dutch waters. This approach has been used widely, including by ASCOBANS and OSPAR, which sets a $1.7 \%$ limit on harbour porpoise mortality as an EcoQO. We calculated limits for $1 \%$ and $1.7 \%$.

Second, we calculated a mortality limit by applying the PBR approach to the average annual abundance estimate for Dutch waters. Following Wade (1998) we calculated the minimum abundance estimate, $N_{\min }$, as the 20th percentile of a log-normal distribution surrounding the abundance estimate, $N$ (equivalent to the lower limit of a $60 \%$ 2-tailed confidence interval):

$$
N_{\text {min }}=N e\left(z \sqrt{\ln \left(1+C V^{2}\right)}\right)
$$

where $C V$ is the coefficient of variation of the abundance estimate and $z=-0.842$, the normal deviate corresponding the 20th percentile. For the PBR calculation, we assumed the default $R_{\max }$ value of 0.04 for cetaceans [6], and we used a recovery factor $\left(\mathrm{F}_{\mathrm{R}}\right)$ of 0.34 . Reference [12] conducted performance-testing simulations of the PBR 
approach for harbour porpoises in the North Sea and determined that a recovery factor of 0.34 gave a $95 \%$ probability of meeting the ASCOBANS objective under a base simulation scenario. Simulation results presented in reference [6] also suggested that a recovery factor around 0.4 would be necessary to achieve $80 \%$ of carrying capacity. However, simulations have also shown that biased estimates of abundance and mortality would require the use of a lower recovery factor $[6,10,12]$.

Third, we calculated mortality limits on the basis of the mortality limits presented by Winship [12] for harbour porpoises in the entire North Sea. We considered the limits reported in that study for the PBR and CLA approaches that would achieve the interim ASCOBANS objective with $95 \%$ probability under a base scenario. Corresponding mortality limits for Dutch waters were calculated by multiplying the North Sea limits by the ratio of the annual average abundance estimate for Dutch waters to the most recent abundance estimate for the North Sea that was used to calculate the North Sea limits $[12,17]$. We did not apply the CLA approach directly to harbour porpoises in Dutch waters because that method is most appropriate at the population level, and time series of abundance and mortality estimates were not available.

\section{Results}

The bycatch limits calculated using the different approaches are shown in Table 2. The two PBR approaches (just Dutch waters and scaling the total limit for the North Sea by the average abundance estimate for Dutch waters) gave very similar results. This is due to the CVs of the two abundance estimates being very similar in this case, but such similar results would not necessarily be expected.

\section{Discussion}

The abundance estimates from aerial surveys of Dutch waters appear generally consistent with SCANSII estimates suggesting that the southward shift in distribution between SCANS in 1994 and SCANSII in 2005 has persisted since.

The mortality limits calculated for Dutch waters ranged from 183 (CLA) to 272 (PBR). In both cases the procedures had been tuned by simulation to meet the long-term conservation objective of maintaining the population above $80 \%$ of carrying capacity with $95 \%$ probability. The limits based on the CLA were slightly lower than for PBR reflecting differences in the data used and the way in which the procedures calculated limits [12]. However, mortality limits would not necessarily be lower under the CLA procedure in all situations.

A fixed $1.7 \%$ of the population estimate gave a mortality limit 3-4 times higher than those from the management procedures and thus cannot be expected to reliably achieve the stated conservation objective in the long-term. Even the more precautionary $1 \%$ adopted by ASCOBANS resulted in a mortality limit more than twice the CLA limit. PBR tuned to the ASCOBANS conservation objective also gave much lower mortality limits for porpoises off the west coast of Canada than $1.7 \%$ of the total population estimate [11] .

Setting limits based on fixed percentages of best estimates can be risky when there are large uncertainties and possible biases [22]. This approach has been justified as either a short term pragmatic approach or as an approach that is easy to explain to stakeholders, but cannot be considered as the best available science. Although there is further work to be done to develop the best procedure for setting limits to harbour porpoise mortality in the North Sea, there seems no justification in continuing

Table 2. Harbour porpoise abundance estimate for the Dutch Continental Shelf $(\mathrm{N})$ and anthropogenic mortality limits for this area based on percentages of the best abundance estimate (1\% and $1.7 \%)$, PBR, and North Sea limits.

\begin{tabular}{|c|c|c|}
\hline & Dutch Continental Shelf (2010/2011) & North Sea (2005) \\
\hline$N$ & $47178^{1}$ & $216415^{2}$ \\
\hline$C V$ & 0.213 & 0.20 \\
\hline$N \min$ & 39519 & 183176 \\
\hline PBR & 269 & $1246^{3}$ \\
\hline PBR (proportion of North Sea ${ }^{4}$ ) & 272 & - \\
\hline CLA & - & $840^{3}$ \\
\hline CLA (proportion of North $\mathrm{Sea}^{4}$ ) & 183 & - \\
\hline ASCOBANS $1 \%$ & 472 & 2164 \\
\hline ASCOBANS 1.7\% & 802 & 3679 \\
\hline
\end{tabular}

${ }^{1}$ Average of survey estimates from July 2010, Oct/Nov 2010 and March 2011 (Table 1). ${ }^{2}$ This estimate was presented in reference [12] and was calculated from SCANS-II data [17] for a 'North Sea' study area that included areas H, J, M, T, U, Y, and parts of areas B, L, and V (Figure 1). ${ }^{3}$ Reference [12]. ${ }^{4}$ Pro-rated to Netherlands waters based on abundance estimates. 
to use a fixed percentage. In addition, ASCOBANS is not the only agreement with conservation objectives concerning harbour porpoises in the North Sea. Other agreements such as the Marine Strategy Framework Directive (MSFD; 2008/56/EC), the Oslo-Paris convention (OSPAR), EC Directive on the Conservation of Natural habitats and of Wild Fauna and Flora (Habitats Directive; 92/43/EC), and the EC Council Regulation 812/2004 within the European Common Fisheries Policy (CFP; EC 2371/2002) all require some assessment of the conservation implications of human caused mortalities.

The anthropogenic mortality limits presented here were calculated either directly from the estimated abundance of porpoises in Dutch waters only (PBR) or indirectly by reducing previously published mortality limits for the entire North Sea on the basis of our estimate of the proportion of the population in Dutch waters (PBR and CLA). Mortality limits based on these approaches would only be expected to achieve conservation objectives at the population level if all nations calculated such limits in the same way, on the basis of proportional abundance estimates for their national waters that corresponded to the same time of year. This is complicated by recent population estimates being available for Dutch waters but not for other parts of the population. Furthermore, the allocation of a population mortality limit among countries would likely need to consider other factors in addition to the distribution of the population (e.g., distributions and timings of sources of mortality). It is also important to note that the mortality limits based on the North Sea limits assumed that the total harbour porpoise abundance in the North Sea was similar in 2010/2011 (years of the Dutch survey) and in 2005 (year of the North Sea survey).

\section{What Does This Mean for the Porpoises in Dutch Waters}

Ideally, anthropogenic mortality would be assessed at the level of the biological population and not just the subset of the population that occurs in national waters. Nevertheless, The Netherlands, as with other European countries, is asked to ensure that the anthropogenic mortality in their waters is limited such that agreed conservation objectives can be met.

Currently an estimate of anthropogenic mortality of porpoises in Dutch waters does not exist. Based on pathological analyses of stranded porpoises there are indications that the number of porpoises that died in the past few years due to human activities may be close to or higher than the limits presented here based on PBR or CLA $[23,24]$.

At the moment anthropogenic removal is often considered synonymously with by-catch. However, anthropogenic removal should include all causes of death due to human activities. Over the last few years a new cause of mortality has been identified in Dutch waters, called "trauma" [23,24]. Animals have been found with cuts from unknown origin, but which are potentially caused by anthropogenic activities. Different possibilities have been discussed, including some type of interaction with propellers, but the true origin remains unknown. Pathological investigations of 274 harbour porpoises (from December 2010 to November 2011) showed that $7 \%$ of all dissected porpoises died due to this cause of mortality, compared to between 10 and $37 \%$ of the dissected porpoises that appeared to have died due to by-catch in fisheries.

The procedures and mortality limits that we considered here focused only on direct mortality and not indirect or sub-lethal effects and their possible population level consequences. A generalization of PBR to also account for the indirect impacts on marine mammals resulting from competition for prey with fisheries has been proposed [25]. Mortality could also increase due to a suppressed immune system, e.g. due to toxic loads in the ecosystem and the animals, thereby increasing the occurrence of infectious illnesses [26,27]. The effects of overall habitat degradation on harbour porpoise populations, e.g. due to an increase in anthropogenic noise in the marine environment, are still unknown. In the future, total cumulative anthropogenic impacts could be considered to ensure that all threats are managed in a way that would be expected to achieve conservation objectives.

Further work is needed to develop explicit rules for setting mortality limits for national waters that do not represent biologically significant boundaries if individual member states wish to set indicators and targets for harbour porpoise by-catch at the national level. The RMP has provisions for spatially distributing catch limits providing a body of work that has considered how best to allocate population mortality limits to smaller spatial areas [7].

\section{Conclusion}

We recommend the use of management procedures for data including associated uncertainties and biases, and whose performance has been extensively tested through simulation. The mortality limits for the Netherlands that we have presented here based on two such procedures (PBR and CLA) and new porpoise abundance estimates for Dutch waters suggest that current approaches to setting harbor porpoise by-catch limits in the North Sea may allow levels of mortality that will not meet internationally agreed conservation objectives.

\section{Acknowledgements}

Funds for this study were provided by the Dutch Ministry 
of for Economic Affairs, Agriculture and Innovation (Statutory Research Tasks Nature and Environment) and IMARES. Thank you to P. Hammond and the SCANSII project and its investigators for their support and contributions to AJW's PhD thesis research. We thank Bram Couperus for reviewing this paper prior to submission, as well as two anonymous reviewers.

\section{REFERENCES}

[1] P. J. H. Reijnders, "Harbour Porpoises Phocoenaphocoena in the North Sea: Numerical Responses to Changes in Environmental Conditions," Aquatic Ecology, Vol. 26, 1992, pp. 1386-2588.

[2] C. J. Camphuysen and M. L. Siemensma, "Conservation Plan for the Harbour Porpoise Phocoenaphocoena in The Netherlands: Towards a Favourable Conservation Status," NIOZ Report 2011-07, Royal Netherlands Institute for Sea Research, Texel, 2011.

[3] ASCOBANS, "ASCOBANS Conservation Plan for Harbour Porpoises (Phocoena phocoena L.) in the North Sea," 6th Meeting of the Parties to ASCOBANS, Bonn, Germany, 16-18 September 2009, 35 pp.

[4] ASCOBANS, "MOP 3: Resolution on Incidental Take of Small Cetaceans," ASCOBANS, Bristol, 2000.

[5] ASCOBANS, "MOP 2: Resolution on Incidental Take of Small Cetaceans," ASCOBANS, Bonn, 1997.

[6] P. R. Wade, "Calculating Limits to Human-Caused Mortality of Cetaceans and Pinnipeds," Marine Mammal Science, Vol. 14, No. 1, 1998, pp. 1-37. doi:10.1111/j.1748-7692.1998.tb00688.x

[7] A. E. Punt and G. P. Donovan, "Developing Management Procedures That Are Robust to Uncertainty: Lessons from the International Whaling Commission," ICES Journal of Marine Science, Vol. 64, No. 4, 2007, pp. 603-612. doi:10.1093/icesjms/fsm035

[8] J. G. Cooke, "Improvement of Fishery-Management Advice through Simulation Testing of Harvest Algorithms," ICES Journal of Marine Science, Vol. 56, No. 6, 1999, pp. 797-810. doi:10.1006/jmsc. 1999.0552

[9] J. Cooke, R. Leaper, P. Wade, D. Lavigne and B. Taylor, "Management Rules for Marine Mammal Populations: A Response to Lonergan," Marine Policy, Vol. 36, No. 2, 2012, pp. 389-392. doi:10.1016/j.marpol.2011.06.009

[10] P. Berggren, P. R. Wade, J. Carlström and A. J. Read, "Potential Limits to Anthropogenic Mortality for Harbour Porpoises in the Baltic Region," Biological Conservation, Vol. 103, 2002, pp. 313-322. doi:10.1016/S0006-3207(01)00142-2

[11] R. Williams, A. Hall and A. Winship, "Potential Limits to Anthropogenic Mortality of Small Cetaceans in Coastal Waters of British Columbia," Canadian Journal of Fisheries and Aquatic Sciences, Vol. 65, 2008, pp. 1867-1878. doi:10.1139/F08-098

[12] A. J. Winship, "Estimating the Impact of Bycatch and Calculating Bycatch Limits to Achieve Conservation Objectives as Applied to Harbour Porpoise in the North Sea," PhD Thesis, University of St Andrews, St Andrews,
2009.

http://research-repository.st-andrews.ac.uk/handle/10023/ 715

[13] C. Smeenk, "The Harbour Porpoise Phocoenaphocoena (L., 1758) in The Netherlands: Stranding Records and Decline. Lutra, Vol. 30, 1987, pp. 77-90.

[14] C. J. Camphuysen, "The Harbour Porpoise Phocoenaphocoena in the Southern North Sea. II: A Come-Back in Dutch Coastal Waters?" Lutra, Vol. 37, No. 1, 1994, pp. 54-61.

[15] C. J. Camphuysen, "Recent Trends and Spatial Patterns in Nearshore Sightings of Harbour Porpoises (Phocoenaphocoena) in The Netherlands (Southern Bight, North Sea), 1990-2010," Lutra, Vol. 54, No. 1, 2011, pp. 37-44.

[16] P. J. H. Reijnders, M. F. Leopold, C. J. Camphuysen, H. J. L. Heessen and R. A. Kastelein, "The Status of the Harbour Porpoise, Phocoenaphocoena, in Dutch Waters and the State of Related Research in the Netherlands: An Overview," Forty-Sixth Report of the International Whaling Commission, 1996, pp. 607-611

[17] SCANS-II, "Small Cetaceans in the European Atlantic and North Sea SMRU," Scottish Oceans Institute, University of St Andrews, 2008.

[18] C. J. Camphuysen, "The Return of the Harbour Porpoise (Phocoenaphocoena) in Dutch Coastal Waters," Lutra, Vol. 47, No. 2, 2004, pp. 113-122.

[19] M. Scheidat, H. Verdaat and G. Aarts, "Using Aerial Surveys to Estimate Density and Distribution of Harbour Porpoises in Dutch Waters," Journal of Sea Research, Vol. 69, 2012, pp. 1-7. doi:10.1016/j.seares.2011.12.004

[20] S. C. V. Geelhoed, M. Scheidat, R. S. A. van Bemmelen and G. Aarts, Abundance of harbour porpoises Phocoenaphocoena on the Dutch Continental Shelf, Aerial Surveys in July 2010-March 2011," Lutra, Vol. 56, No. 1, 2013, pp. 45-57.

[21] P. G. H. Evans and J. Teilmann, "Report of ASCOBANS /HELCOM Small Cetacean Population Structure Workshop," Bonn, 8-10 October 2007.

http://unep-ascobans.org/pdf/Report_PopulationStructure Workshops2007_small.pdf

[22] B. Taylor, "'Best' Abundance Estimates and Best Management: Why They Are Not the Same," US Department of Commerce, NOAA Technical Memorandum NMFSSWFSC-188, 1993, 20 pages.

[23] A. Gröne, L. Begeman and S. Hiemstra, "Postmortaal Onderzoek van Bruinvissen in Nederlandse Wateren 20092011. Report for the Ministerie van Economische Zaken, Landbouw \& Innovatie," Verplichting nummer: 140000 353; Relatie nummer 101710, 2011.

[24] M. Scheidat and M. Van den Heuvel Greve, "Annual National Report The Netherlands," 19th ASCOBANS Advisory Committee Meeting, Galway, 20-22 March 2012. http://www.ascobans.org/pdf/ac19/AC19_2-07_National ReportNetherlands.pdf

[25] J. E. Moore, "Management Reference Points to Account for Direct and Indirect Impacts of Fishing on Marine Mammals," Marine Mammal Science, 2012, in Press. doi:10.1111/j.1748-7692.2012.00586.x 
[26] P. D. Jepson, P. M. Bennett, R. Deaville, C. R. Allchin, J. R. Baker and R. J. Law, "Relationships between Polychlorinated Biphenyls and Health Status in Harbor Porpoises (Phocoenaphocoena) Stranded in the United Kingdom," Environmental Toxicology and Chemistry, Vol. 24, No. 1, 2005, pp. 238-248. doi:10.1897/03-663.1

[27] G. J. Pierce, M. B. Santos, S. Murphy, J. A. Learmonth, A. F. Zuur, E. Rogan, P. Bustamante, F. Caurant, V. Lahaye, V. Ridoux, B. N. Zegers, A. Mets, M. Addink, C. Smeenk, T. Jauniaux, R. J. Law, W. Dabin, A. López, J.
M. Alonso Farré, A. F. González, A. Guerra, M. GarcíaHartmann, R. J. Reid, C. F. Moffat, C. Lockyer and J. P. Boon, "Bioaccumulation of Persistent Organic Pollutants in Female Common Dolphins (Delphinusdelphis) and Harbour Porpoises (Phocoenaphocoena) from Western European Seas: Geographical Trends, Causal Factors and Effects on Reproduction and Mortality," Environmental Pollution, Vol. 153, No. 2, 2008, pp. 401-415.

doi:10.1016/j.envpol.2007.08.019 